\title{
Índice de letalidad 2008-2014: menos enfrentamientos, misma letalidad, más opacidad
}

\author{
Carlos Silva Forné, ${ }^{*}$ Catalina Pérez Correa, ${ }^{* *}$ Rodrigo Gutiérrez Rivas ${ }^{* * *}$
}

Perfiles Latinoamericanos, 25(50)

2017 | pp. 331-359

DOI: $10.18504 / \mathrm{pl} 2550-015-2017$

\begin{abstract}
Resumen
Este artículo evalúa el uso de la fuerza letal por parte de las fuerzas federales mexicanas en enfrentamientos con presuntos miembros de la delincuencia organizada en el periodo 20082014. Con datos oficiales y reportes de prensa sobre muertos y heridos en enfrentamientos se construyen indicadores acerca del uso de la fuerza letal. En un contexto donde aumentan o se mantienen constantes los factores que favorecen el uso excesivo de la fuerza letal, los resultados muestran una esperada tendencia al alza en sus valores, lo que consolida un posible patrón sistemático de uso ilegal de la fuerza letal por parte de las fuerzas federales de seguridad. Además, se plantea que existe una creciente opacidad en la información oficial disponible y serias carencias en el marco legal que regula el uso de la fuerza.
\end{abstract}

\begin{abstract}
This article evaluates the use of lethal force by Mexican federal security forces during shootings with presumed members of organized crime from 2008-2014. The authors use official data and press reports on deaths and wounded in shootings to construct indicators such as the number of dead civilians over the number of dead officials from the federal security forces and the number of dead civilians over the number of wounded civilians. In a context where certain factors that contribute to an excessive use of force become more common, the results of the study show a growing use of lethal force. This raises questions over the possible excessive use of lethal force as a normal or systematic practice. The study also shows a growing context of opacity in the information available to evaluate the use of lethal force and the general lack of a legal framework to regulate the use of lethal force in Mexico.
\end{abstract}

Palabras clave: uso de la fuerza, índice de letalidad, fuerzas federales, delincuencia organizada, transparencia, derecho a la vida.

Keywords: Use of force, lethality index, federal forces, organized crime, right to information, right of life.

* Doctor en Ciencias Sociales por El Colegio de México, A.C. Profesor Investigador del Instituto de Investigaciones Jurídicas (UNAM) | carlos_silvaforne@yahoo.com.mx

** Doctora en Derecho por la Universidad de Stanford, California. Profesora Investigadora del Centro de Investigación y Docencia Económicas (CIDE) | catalina.perezcorrea@gmail.com

*** Doctor en Derecho por la Universidad Complutense de Madrid. Profesor Investigador del Instituto de Investigaciones Jurídicas (UNAM) | rod_gtz@hotmail.com 
Desde el lugar en el que se encontraba V23, refiere haber visto a tres militares: uno que se encontraba enfrente de la camioneta gris, que estaba pegada al muro izquierdo de la bodega (norte), otro que estaba cercano al muro y a la bodega que portaba una lámpara, y un tercero que salió desde el interior del cuarto al que ingresaron a las personas rendidas, junto con uno de los jóvenes; él los llevaba hacia el militar que tenía la lámpara, les preguntaban de dónde eran, su edad, su apodo, y posteriormente, les disparaban. Ella pudo escuchar cómo se quejaban.

(CNDH, recomendación 51/2014, punto 152 )

\section{Introducción ${ }^{1}$}

E

30 de junio de 2014, diversos medios reportaron un enfrentamiento entre elementos de la Secretaría de la Defensa Nacional (Sedena) y presuntos miembros de la delincuencia organizada en la comunidad de San Pedro Limón, municipio de Tlatlaya, Estado de México. El saldo del enfrentamiento fue de 22 civiles muertos (incluida una adolescente de quince ańos) y un soldado herido. Tras realizar las diligencias correspondientes, la Procuraduría General de Justicia del Estado de México (PGJEM) afirmó, a través de un comunicado (Ferri, 2014), que el intercambio de disparos fue proporcional entre ambos bandos. El 19 de septiembre, ante la aparición de una testigo presencial, la revista Esquire reportó que las muertes ocurridas en Tlatlaya podrían tratarse de privaciones arbitrarias de la vida por parte del Ejército Mexicano. El reportaje dio pie a diversas indagaciones y la apertura de una investigación por parte de la Comisión Nacional de Derechos Humanos (CNDH). El 21 de octubre, mediante la recomendación 51/2014, dicho organismo señaló que, dadas las investigaciones, podía afirmarse que había existido la privación ilegal de la vida y la alteración de la escena del crimen por parte de los miembros del Ejército, "con la intención, muy probablemente, de simular que las muertes habían ocurrido en un contexto de enfrentamiento" (CNDH, 2014: punto 119). ${ }^{2} \mathrm{El} 26 \mathrm{de}$

1 Agradecemos la colaboración de Karen Silva, Fernando Gómez y José Luis Torres.

2 El organismo declaró también que "además de las violaciones a derechos humanos cometidas por personal militar que participó en los hechos, este Organismo Nacional logró acreditar la tortura y agresio- 
septiembre, como respuesta ante la presión nacional e internacional, el secretario de Gobernación señaló que, de tratarse de privaciones ilegales de la vida, era una excepción y no una práctica común del Ejército (Reforma, 26 de septiembre de 2014).

El caso Tlatlaya cobró notoriedad pública y atención institucional más de dos meses después de los hechos como consecuencia de investigaciones periodísticas, pero el evento en cuanto "enfrentamiento entre fuerzas de seguridad federales y presuntos miembros de la delincuencia organizada" fue uno más entre miles que han acontecido en casi una década de conflicto en México. Desde los primeros años de la administración de Felipe Calderón, en el marco de la "guerra contra el narcotráfico", se hicieron cotidianas las notas de prensa que daban a conocer que elementos del Ejército (o de la Policía Federal o de la Marina) habían sido agredidos y ello suscitaba un enfrentamiento con un saldo habitual de muchos agresores muertos y pocos heridos.

Los enfrentamientos producto de una agresión hacia las fuerzas de seguridad resultaron en la construcción de un marco legitimador para el uso de la fuerza sin generar una investigación posterior. Es decir, si un enfrentamiento se consideraba legítimo, no parecía necesaria su investigación, de las bajas que causara o de la participación de las fuerzas que tomaron parte. Esto tiene como resultado la imposibilidad de evaluar la legalidad y/o proporcionalidad en el uso de la fuerza, como se ha notado en contextos distintos al mexicano tal como en Venezuela (Del Olmo, 1990, Birkbeck \& Gabaldon, 2002), Argentina (Chevigny, 1995; CELs, 2002), Brasil (Cano, 1997, 2004, 2010), Guyana (Mars, 2002), Estados Unidos (Skolnick \& Fyfe, 1993) o India (Belur, 2010).

$\mathrm{Si}$ el uso de la fuerza letal ocurre en un contexto de "guerra", sin que se genere información y se investigue sancionando el mal uso, es probable que dicho uso muestre incrementos, conforme aumente la activa participación en tareas de seguridad pública de fuerzas militares, tal como ocurrió en México desde 2006. Ello podría alertar sobre un posible patrón sistemático de uso excesivo de la fuerza letal ya sea como práctica normalizada o como política deliberada de actuación.

La situación en México desde 2007 presenta varios factores que permiten hipotetizar sobre el aumento del uso excesivo de la fuerza letal por parte de las fuerzas federales de seguridad, a saber:

nes sexuales cometidas por parte de personal adscrito a la Procuraduría General de Justicia del Estado de México [...] así como diversas irregularidades durante la integración de la carpeta de investigación." (CNDH, 2014: punto 118). 
a) La presencia de una delincuencia violenta que representa un riesgo real para las fuerzas de seguridad. ${ }^{3}$

b) Un discurso de "guerra" en contra de la delincuencia que en el caso mexicano fue impulsado desde el propio Ejecutivo federal y apoyado por buena parte de los actores políticos, económicos y sociales del país. ${ }^{4}$ Este discurso ha adoptado características del derecho penal del enemigo. ${ }^{5}$

c) El respaldo de una parte significativa de la población a prácticas como la tortura o las ejecuciones extrajudiciales como mecanismo para combatir la delincuencia organizada. ${ }^{6}$

d) Un sistema de justicia que no investiga la enorme mayoría de los casos en los que las fuerzas de seguridad utilizan la fuerza con resultados letales, por lo que el uso excesivo queda impune. ${ }^{7}$

e) La cada vez mayor participación y despliegue de fuerzas preparadas para la guerra como el Ejército y la Marina en tareas de seguridad pública local. ${ }^{8}$

El uso de la fuerza letal se puede evaluar con base en distintos indicadores. Los más comunes a nivel internacional (Loche, 2010: p. 45) son: a) el porcentaje de homicidios dolosos cuyo presunto responsable es un policía o miembro de otra fuerza de seguridad, $b$ ) número de civiles muertos por cada policía o miembro de otra fuerza de seguridad muerto en enfrentamientos, $\mathrm{y} c$ ) número de civiles muertos por cada civil herido en enfrentamientos. El análisis de más

3 Véase Guerrero $(2010,2011)$.

4 En su primer día como presidente, Felipe Calderón declaró: "Sé que restablecer la seguridad no será fácil ni rápido, que tomará tiempo, que costará mucho dinero, e incluso por desgracia, vidas humanas. Pero téngalo por seguro, ésta es una batalla en la que yo estaré al frente, es una batalla que tenemos que librar y que unidos los mexicanos vamos a ganar a la delincuencia" (citado por Astorga, 2015: p. 21); y en enero de 2007, en la xxi sesión del Consejo Nacional de Seguridad: "Para ganar la guerra contra la delincuencia es indispensable trabajar unidos, más allá de nuestras diferencias, más allá de cualquier bandera partidista y de todo interés particular" (citado por Astorga, 2015: p. 23). Acerca del apoyo de buena parte de los actores políticos, económicos y sociales en la "guerra contra la delincuencia", véase Astorga (2015: p. 25 y ss.).

5 Véase Salazar (2012).

6 Según la Encuesta de Cultura Constitucional (IIJ-UNAM) de 2011, casi la tercera parte de los entrevistados (31.7\%) dijeron estar de acuerdo con que "las fuerzas de seguridad maten a una persona miembro de la delincuencia organizada aunque exista la posibilidad de presentarlo ante la justicia". En la Encuesta de Seguridad Pública de la colección "Los mexicanos vistos por sí mismos" (UNAM) de 2015, la misma frase obtuvo el acuerdo de la cuarta parte de los entrevistados (24.2\%). Sin embargo, en 2015 la categoría de respuesta que aumentó ante el leve descenso del "acuerdo" fue la de quienes no están "ni de acuerdo ni en desacuerdo", resultando que tanto en 2011 como en 2015 quienes rechazaron que las fuerzas de seguridad realicen una ejecución extrajudicial no superaron la mitad de los entrevistados (48 y $47 \%$, respectivamente) (Jiménez \& Silva: 2015).

7 Véase, por ejemplo, México Evalúa (2012) y United States Department of State (2015).

8 En el próximo apartado se muestra el aumento del número de personal y operativos de fuerzas federales durante la mayor parte de periodo bajo estudio. 
de un indicador deriva en mayor certeza acerca del uso excesivo de la fuerza letal por parte de una fuerza de seguridad (Cano, 2003). En este artículo, estudiamos la relación entre civiles muertos sobre miembros de fuerzas de seguridad muertos en enfrentamientos y en particular la relación entre civiles muertos y civiles heridos en enfrentamientos: el índice de letalidad.

En 2011 los autores del este texto realizamos una primera evaluación del uso de la fuerza letal por parte de las autoridades federales entre 2008 y 2011 (Silva, Pérez \& Gutiérrez: 2012). Aquí, como en la primera evaluación, definimos la relación entre civiles muertos sobre civiles heridos en enfrentamientos como indice de letalidad, siguiendo la terminología de Cano (1997, 2003, 2010) para estudios en Brasil. El análisis del indicador tiene antecedentes en Chevigny $(1987,1991,1993)$ y ha sido retomado en Argentina (CELs, 2002; Sozzo, 2002; Aimar et al., 2005) y Venezuela (Birkbeck \& Gabaldón, 2002). Se espera que en enfrentamientos entre civiles y cuerpos de seguridad, el número de muertos no sea significativamente superior al número de heridos y por tanto que el índice sea cercano o inferior a uno.

Han transcurrido cuatro años desde dicho estudio y un cambio de administración a nivel presidencial. Enrique Peña Nieto inició su gobierno con un discurso menos belicoso que el del gobierno de Calderón. Este cambio parecía implicar un gradual retiro del Ejército mexicano de las labores de seguridad pública. Sin embargo, los casos de Tlatlaya, Apatzingán y Ecuandureo/Tanhuato, han traído de nuevo al debate público las preocupaciones sobre la continuación del uso excesivo de la fuerza letal por parte del Ejército y otras fuerzas federales, así como su posible carácter sistemático y normalizado.

En este marco, nos propusimos generar nueva información sobre muertos y heridos en enfrentamientos en los que participaron las fuerzas federales (Policía Federal, Ejército y Marina) y estudiar los posibles cambios entre la pasada administración y la actual. Para ello, igual que en nuestro estudio de 2011, construimos una base de datos a partir de reportes de prensa y solicitamos información sobre el tema a las distintas instituciones de seguridad federal (Secretaría de la Defensa, Secretaría de Marina, Policía Federal y Procuraduría General de la República).

Los resultados, aunque alentadores en algunos aspectos, advierten una situación general de preocupación. Encontramos que la presente administración, comparada con la anterior, muestra un menor número de enfrentamientos y muertos en enfrentamientos, sin embargo, no puede decirse lo mismo de su letalidad que se mantienen en valores altos y preocupantes para todo el país. Esto rige en especial para algunas entidades como Guerrero y Zacatecas donde el índice de letalidad alcanza valores muy elevados. Asimismo, la Policía Federal reporta un índice muy elevado en 2013, a partir de cifras oficiales, 
y en 2014 con base en datos de prensa, lo que obliga a preguntarse por el desempeño de dicha institución durante la actual administración. Por último, encontramos una creciente opacidad por parte de la Sedena, lo que implica otra señal de alarma dado el contexto de violencia, los altos valores de los indicadores correspondientes al Ejército, y los recientes enfrentamientos en los que ha participado esa institución y que han dejado saldos de muchos civiles muertos y pocos heridos como en el caso de Tlatlaya, Estado de México, o el de Río Bravo, Tamaulipas.

Este artículo se divide en seis partes, la primera es esta introducción. En la segunda, se dan varias precisiones metodológicas; en la tercera presentamos los principales resultados del estudio; en la cuarta relatamos las dificultades para conseguir información que permita un análisis mínimo del uso de la fuerza letal por parte del Estado; la quinta la dedicamos a describir el actual marco legal que rige el uso de la fuerza letal y, finalmente, concluimos con algunas reflexiones sobre la información y nuestro análisis.

\section{Precisiones metodológicas}

\section{Índice de letalidad 2008- 2011}

El índice de letalidad 2008-2011 se calculó con información de prensa para el periodo enero de 2008 a mayo de 2011 (Silva, Pérez \& Gutiérrez: 2012). ${ }^{9}$ Encontramos que durante ese periodo el Ejército tuvo un saldo de 9.1 civiles muertos por cada civil herido en enfrentamientos, la Policía Federal 2.6 civiles muertos por cada civil herido y la Marina 17.3 civiles muertos por cada herido (aunque esta última institución con muy pocos casos reportados en prensa durante el periodo). Por las limitaciones en cobertura y posibles sesgos de la fuente utilizada ${ }^{10}$ se compararon los resultados que arrojaba la base de prensa con datos proporcionados por la Sedena obtenidos vía acceso a la información. ${ }^{11}$

De acuerdo con los datos de la Sedena, el índice de letalidad fue más bajo (6.3) que el calculado con datos de prensa (9.1). Sin embargo, de valores de 2.7 en 2008 y 3.0 en 2009 se pasó a otros significativamente más elevados en 2010

9 Para ver la metodología de construcción de la base véase Silva, Pérez \& Gutiérrez (2012).

10 La información de la prensa acerca de los enfrentamientos suele privilegiar los casos más violentos con un mayor número de muertos y excluir aquellos donde solo hubo heridos; tal sesgo aumenta el valor del índice de letalidad.

11 Más de tres cuartas partes de los enfrentamientos registrados en la base de datos de prensa eran con participación del Ejército por lo que en esa ocasión solo se pidió información a dicha dependencia. 
(6.8) y 2011 (6.5), y en algunas entidades federativas para 2011 llegó a 10.2 (en Tamaulipas) y 9.4 (en Guerrero) (Silva, Pérez \& Gutiérrez: 2012: pp. 59-60).

El índice de letalidad se ha utilizado en otros países. Por ejemplo, en Brasil se ha recurrido al cálculo de la relación entre civiles muertos y civiles heridos para evaluar el uso de la fuerza de las policías (en particular, en São Paulo y Río de Janeiro) (Chevigny, 1987, 1993; Cano, 1997, 2010). En sus estudios, Cano (2010: p. 37) muestra que para la Policía Militar de Río de Janeiro, ${ }^{12}$ entre 1993 y 1996, el índice de letalidad fue de 3.9; sin embargo, al interior de las favelas y en enfrentamientos con personas de raza negra o mulata, el índice alcanzaba a 8 o 9 civiles muertos por cada civil herido (Cano, 2010). De acuerdo con el autor, índices de letalidad tan elevados sugerían la existencia de ejecuciones extrajudiciales. El índice del letalidad del Ejército en México para los años 2010 y 2011 (6.8 y 6.5, respectivamente), según los datos de la Sedena, fue superior al de la Policía Militar de Río de Janeiro a mediados de la década de los noventa (3.9); y los valores alcanzados en Tamaulipas (10.2) y Guerrero (9.4) superaron a los del estado de Río de Janeiro al considerar las categorías de raza y espacio de ocurrencia que más agravan la letalidad del uso de la fuerza.

No existen indicadores únicos que conduzcan a determinar si en una situación se llevaron a cabo ejecuciones extrajudiciales o si una fuerza de seguridad en su conjunto está usando de modo excesivo y desproporcionado la fuerza letal. Sin embargo, hay aproximaciones que permiten evaluar las actuaciones de las distintas fuerzas de seguridad. Para poder comprobar en un caso concreto la existencia de ejecuciones extrajudiciales debe evaluarse la información detallada sobre cada acontecimiento (Alston, 2006, 2010). En este sentido, cada vez que el Estado hace un uso letal de la fuerza, es indispensable que las instituciones de procuración y administración de justicia emprendan las investigaciones correspondientes. En el contexto mexicano, sin embargo, y como muestran los datos que aquí se presentan, cada muerte no lleva aparejada un investigación civil. Más bien, al afirmarse que los enfrentamientos resultaron de agresiones a las fuerzas de seguridad, se dispensa de las investigaciones civiles correspondientes que pudieran determinar las características concretas del uso de la fuerza. En este contexto de impunidad generalizado surge la necesidad de construir indicadores que evalúen el uso legítimo y proporcional de la fuerza letal por parte de los distintos cuerpos de seguridad. No se trata de indicadores que por sí mismos determinen si hay privaciones arbitrarias de la vida, sino de valores que alertan sobre un contexto de preocupación y que muestran la necesidad de investigaciones serias y puntuales para cada caso.

12 El análisis se realizó principalmente con información oficial contenida en reportes de incidentes policiales y reportes forenses (Cano, 2010: p. 36). 
Para el análisis del índice 2007-2014 usamos dos fuentes: i) información proporcionada vía Infomex por la Policía Federal, la Sedena, la Marina y la PGR sobre el número de enfrentamientos con grupos de delincuencia organizada, y el número de civiles muertos y heridos en dichos enfrenamientos entre 2007 y $2014 ;{ }^{13}$ ii) asimismo, se elaboró una base de datos con las mismas variables con información de prensa ${ }^{14}$ sobre enfrentamientos entre fuerzas federales y presuntos miembros de la delincuencia organizada durante el mismo periodo. En este último caso, es importante considerar que la información de prensa, por sus criterios de selectividad, suele tener un sesgo al alza de los indicadores que analizamos, por ello es importante utilizarla con cautela y compararla con los datos oficiales. A diferencia del estudio de 2011, en esta ocasión encontramos importantes dificultades para obtener información sobre la actuación de la Sedena, lo que apunta una mayor opacidad en esta institución.

\section{Resultados}

Los principales resultados se presentan divididos en: 1) evolución del número de enfrentamientos durante el periodo 2008-2014, 2) número de civiles muertos sobre número de miembros de fuerza de seguridad muertos en enfrentamientos, 3) índice de letalidad por fuerza de seguridad y su evolución durante el periodo 2008-2014, y 4) índice de letalidad en entidades federativas.

1) Número de enfrentamientos de 2008 a 2014. Existen importantes variaciones en este dato a lo largo del periodo: tuvo un crecimiento acelerado de 2007 a 2011 para luego descender en 2012 y profundizarse esta baja en 2013 y 2014. En el gráfico 1 se observan las variaciones para cada una de las fuerzas federales de seguridad.

13 El 27 de octubre de 2014 se realizaron solicitudes de información a las siguientes dependencias: Secretaría de la Defensa Nacional, folio 0000700211714; Secretaría de Marina, folio 0001300092314, y Policía Federal, folio 0413100088114.

14 Para la construcción de la base de datos de prensa se revisaron los archivos digitales de dos periódicos de distribución nacional: El Universal y La Jornada. Si las cifras de muertos o heridos no coincidían en los dos periódicos, se consultaba un tercero de distribución nacional, Reforma, o un cuarto, La Crónica de Hoy. Si las cifras continuaban sin coincidir se recurría a una regla de registro por la que se debía considerar el menor número de muertos y el mayor número de heridos. 
Gráfico 1. Total de enfrentamientos con presuntos miembros de la delincuencia organizada por tipo de fuerza de seguridad (2008-2014)

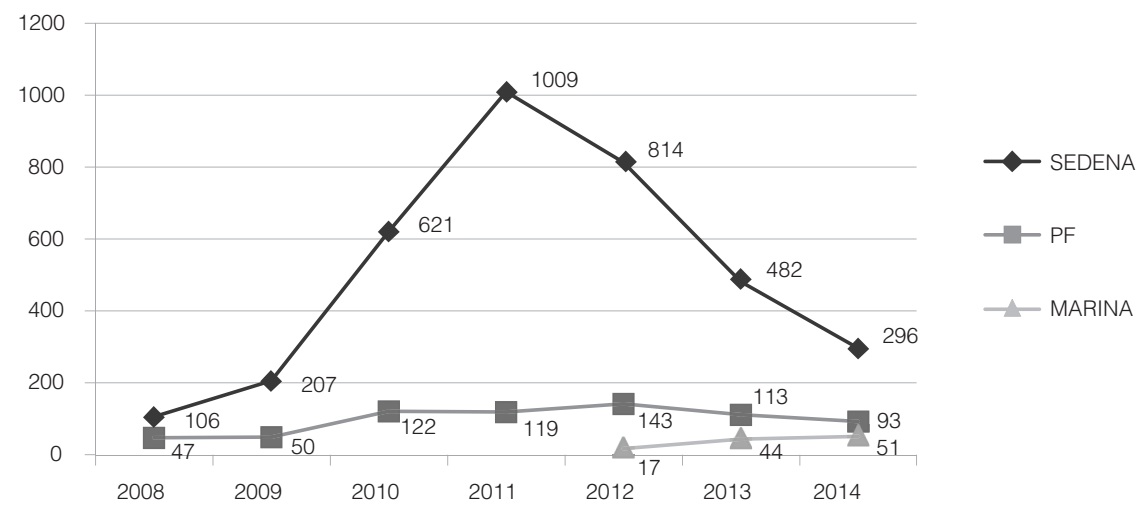

* Para 2014 los datos proporcionados por el Ejército y la Policía Federal fueron hasta octubre, y hasta septiembre por parte de la Marina. Para cada fuerza se completó el total del año siguiendo la tendencia de los meses previos.

Fuente: Elaboración propia con información de las solicitudes 0000700211714 (Sedena), 0001300092314 (Marina) y 0413100088114 (Policía Federal).

Como muestra el gráfico 1, la Sedena alcanza el máximo número de enfrentamientos en 2011 lo que luego se reduce en $70 \%$ a lo largo de los tres siguientes ańos. La Policía Federal, con cifras menores y estables, tuvo un crecimiento de 2008 a 2012 para después descender 35\% en dos ańos. Finalmente, si bien la información brindada por la Marina es limitada y su participación más reducida, el número de enfrentamientos de dicha dependencia en 2013 y 2014 fue mayor que en 2012.

Destacan el alza de los enfrentamientos hasta 2011, casi hasta el final del gobierno de Calderón, y el descenso continuo (iniciado en 2012) en los dos primeros años del de Peña Nieto. ${ }^{15}$ Esta última y significativa disminución podría explicarse por distintas razones, por ejemplo: menor despliegue de las fuerzas federales, variaciones en la cantidad y características de los operativos implementados (verbigracia, los retenes), y la reconfiguración y/o desplazamientos de los grupos delincuenciales a regiones o tareas que propicien un menor contacto con fuerzas federales de seguridad. ${ }^{16}$

15 La información de prensa revisada solo captó el 15\% de los enfrentamientos reportados por las cifras oficiales para el periodo, pero las tendencias son las mismas. En el caso del Ejército se registraron 26 enfrentamientos en 2008, cifra que aumenta a 129 en 2011 para descender a 43 en 2014.

16 Guerrero (2015) sugiere que la "disminución de la incidencia delictiva puede estar relacionada con el desplazamiento de la violencia del crimen organizado fuera de las principales zonas metropolitanas del país." Esto implicaría un menor contacto con los cuerpos de seguridad y, por tanto, menos enfrentamientos.

C. Silva Forné, C. Pérez Correa, R. Gutiérrez Rivas | Índice de letalidad 2008-2014: menos enfrentamientos, misma letalidad, más opacidad | Perfiles Latinoamericanos, 25(50) | FLAcso México | pp. 331-359 
Tomemos la primera variable, esto es, el despliegue de las fuerzas federales. Para la Sedena, de 2006 a 2011 hubo un constante incremento en el número de elementos desplegados en operaciones ${ }^{17}$ contra el narcotráfico y la delincuencia organizada, lo cual llegó a 52690 elementos en 2011. En cambio, para 2012 y 2013 muestran un descenso significativo, que aumentó ligeramente en 2014. En términos de operaciones, su número aumenta de 2007 a 2009 para luego mantener valores similares hasta 2012, aunque levemente inferiores).

Tabla 1. Elementos desplegados y operaciones contra el narcotráfico y la delincuencia organizada. Sedena 2006-2014

\begin{tabular}{lccc}
\hline Año & Elementos desplegados (promedio) & Año & No. de operaciones \\
\hline 2006 & 37.253 & - & - \\
2007 & 45.000 & 2007 & 28 \\
2008 & 45.106 & 2008 & 56 \\
2009 & 48.650 & 2009 & 98 \\
2010 & 49.650 & 2010 & 89 \\
2011 & 52.690 & 2011 & 87 \\
2012 & 49.650 & 2012 (ene-nov) & 92 \\
2013 & 34.529 & 2012(dic)-2014(dic) & 14 \\
2014 & 35.615 & & \\
\hline
\end{tabular}

Fuente: Elementos desplegados: Sedena, respuesta a solicitud folio 0000700211414. Operativos: a) 2007-2012: Sedena, respuesta a solicitud folio 0000700008513; b) 2012-2014: Sedena, respuesta a solicitud folio 0000700211414 .

Para el periodo diciembre 2012-diciembre 2014, la información oficial se dio de forma agregada y reportó solo catorce operaciones, una cifra llamativamente menor a la de años anteriores. Queda abierta la interrogante acerca de un posible cambio en la definición del término "operaciones" u otras razones que explicaran tan marcado descenso.

La caída en el número de elementos desplegados corre en paralelo con el descenso de los enfrentamientos por parte del Ejército. Sin embargo, precisar

17 En respuesta a la solicitud de información número 0000700211414, en la que se pedía la cantidad de operativos, la Sedena respondió "El personal de esta Secretaría no realiza operativos, toda vez que de conformidad con los artículos 21 de la Constitución Política de los Estados Unidos Mexicanos y $2^{\circ}$ de la Ley General del Sistema de Seguridad Pública, la seguridad pública es una función a cargo de la federación, el Distrito Federal, los estados y municipios, por lo que esta Secretaría sólo actúa en coadyuvancia previa solicitud expresa y motivada de esas autoridades. Este instituto armado realiza sus actividades para defender la integridad, la independencia y soberanía de la nación, mediante la protección y vigilancia del territorio y espacio aéreo nacionales, así como, mediante actividades para reducir los índices de violencia en el país, en el cual se incluye la seguridad a instalaciones estratégicas, tareas de erradicación e intercepción en aplicación de la Ley Federal de Armas de Fuego y Explosivos, así mismo en apoyo a la seguridad pública, fortalecimiento de identidad nacional, servicio militar nacional, protección al medio ambiente y recursos naturales, aplicación del plan III-E y labor social”. En esa solicitud aportó información sobre operaciones realizadas. 
estas relaciones requiere de más información que permita incorporar otras posibles variables involucradas, pero que están fuera del alcance de este artículo.

La disminución de los enfrentamientos trajo consigo, como era de esperarse, menores totales de muertos y heridos en todo el país como consecuencia de tales eventos. El total de presuntos delincuentes muertos por el Ejército en enfrentamientos (según las cifras de la Sedena) pasó de 1297 en 2011 a 459 en $2013 .{ }^{18}$ Este importante descenso es un resultado que se mueve en una dirección deseada. Sin embargo, ello no implica un cambio en otros indicadores acerca del uso de la fuerza letal, los cuales se mantienen en valores preocupantes para todas las instituciones estudiadas.

2) Relación civiles muertos/miembros de fuerzas federales muertos en enfrentamientos. De acuerdo con Chevigny (1991), la muerte de más de diez o quince civiles por cada agente de seguridad fallecido en enfrentamientos sugiere que la fuerza letal se está utilizando más de lo necesario. Los resultados para México en el periodo se muestran en la tabla 2.

Tabla 2. Civiles muertos/policías o soldados muertos en enfrentamientos (2008-2014)

\begin{tabular}{lcc}
\hline & Policía Federal & Ejército \\
\hline 2008 & 1.1 & 5.1 \\
2009 & 2.6 & 17.6 \\
2010 & 3.5 & 15.6 \\
2011 & 9.4 & 32.4 \\
2012 & 10.4 & 23.5 \\
2013 & 6.7 & 20 \\
2014 & $5.1^{\star *}$ & $5.4^{*}$ \\
\hline
\end{tabular}

* El Ejército reportó datos de muertos y heridos en enfrentamientos de enero al 5 de abril de 2014.

** La Policía Federal reportó datos de muertos y heridos en enfrentamientos de enero a octubre de 2014

Fuente: Elaboración propia con información de las solicitudes 0000700211714 y 0413100088114

Para la Policía Federal, la relación de civiles muertos/policías muertos crece hasta alcanzar su valor más alto en 2012 (10.4) y luego desciende en los dos primeros años de la administración peñista. Sin embargo, los datos de prensa

18 Tomamos el dato de civiles muertos de 2013 porque la Sedena solo informó de muertos y heridos hasta marzo de 2014. Los datos de prensa mostraron una tendencia similar a los de la Sedena: el total anual de civiles muertos en enfrentamientos con el Ejército pasó de 653 en 2011 a 238 en 2014. Las cifras de civiles muertos en enfrentamientos derivados de la revisión de prensa son alrededor del $50 \%$ de las oficiales. El hecho de que la prensa nacional revisada haya captado 15\% de los enfrentamientos pero 50\% de las muertes de civiles, refleja la selección de los casos más violentos, lo que evidencia las dificultades implícitas y la cautela que debe guiar el uso de esta fuente.

C. Silva Forné, C. Pérez Correa, R. Gutiérrez Rivas | Índice de letalidad 2008-2014: menos enfrentamientos, misma letalidad, más opacidad | Perfiles Latinoamericanos, 25(50) | FLAcso México | pp. 331-359 
muestran un aumento de este indicador en 2014 y no la disminución de los datos oficiales. Las cifras de prensa siguen una tendencia similar de aumento de la relación civiles muertos/policías muertos en enfrentamientos desde 2008 (2.4) hasta 2012 (16.2); en 2013 el valor desciende a 7.2, pero aumenta en 2014 a 17 civiles muertos por cada policía muerto. ${ }^{19}$

Para el Ejército, según los datos oficiales, el valor más elevado del indicador ocurre en 2011 (32.4). Sin embargo, desde 2009 hasta 2013 se supera el umbral de preocupación de más de quince civiles muertos por cada miembro de la fuerza de seguridad muerto seńalado por Chevigny (1991). El descenso de la relación civiles muertos/soldados muertos en enfrentamientos en 2014 (5.4) debe tomarse con reserva, ya que la Sedena solo brindó información del primer trimestre del año (tal como se explica más adelante) por lo que, por ejemplo, el caso Tlatlaya quedó fuera de la información brindada.

Si recurrimos a la base de datos de prensa para la Sedena, la información muestra un importante aumento del indicador de 2008 (5.5) a 2012 (42.1). En el primer año de la presente administración (2013), la relación de civiles muertos sobre soldados muertos en enfrentamientos disminuyó a 18.8, pero en 2014 subió a 53 civiles muertos por cada soldado muerto en enfrentamientos (159 civiles y 3 soldados fallecidos). Recordemos que la información de prensa suele sobreestimar los indicadores que analizamos. No obstante, ante la ausencia de información oficial después de 2014, esos datos son casi los únicos disponibles para analizar el uso de la fuerza letal.

La información oficial entregada por la Secretaría de Marina (Semar) presenta problemas que no nos permiten construir los indicadores que estamos analizando. ${ }^{20}$ Si consideramos la información de prensa, el valor de la relación civiles muertos/marinos muertos en enfrentamientos es siempre muy elevado. Incluso en 2010 y 2013 no se puede calcular el dato porque no se registraron marinos fallecidos (en 2010 se reportaron 50 civiles muertos en enfrentamientos y 33 en 2013). Dichos valores para los demás años son: 24 para 2009, 34.3 para 2011, 36 para 2012 y 74 para 2014. Se trata pues de valores muy elevados que se han mantenido en los dos años del gobierno de Peña, alcanzando incluso su techo en 2014.

19 El número de civiles muertos es menor en 2013 y 2014 en comparación con los picos de 2011 y 2012, pero llama la atención que las cifras oficiales de la Policía Federal señalen menos civiles muertos en enfrentamientos en 2014 (41) que los registrados en el seguimiento de la prensa nacional (51), misma que reporta un número sensiblemente menor de enfrentamientos. Este último dato subraya la necesidad de continuar obteniendo información de diversas fuentes para la construcción de este y otros indicadores y comparar su evolución en los próximos años.

20 La Semar brindó información sobre los enfrentamientos en los que participó desde marzo de 2012 a septiembre de 2014. Sin embargo, en el 90\% de las casillas correspondientes a la variable "personal naval muerto" y en $85 \%$ de las casillas de la variable "civiles heridos" el oficio de respuesta coloca las letras "s/d" (sin datos). Los casos con información completa son marginales. 
3) Índice de letalidad de las fuerzas federales 2007-2014. Este índice, como ya se mencionó, corresponde al número de civiles muertos por cada civil herido en enfrentamientos. Se esperaría que en enfrentamientos entre civiles y cuerpos de seguridad, la cantidad de muertos no sobrepasara por mucho al de heridos y por tanto que el valor del índice no fuera muy superior a uno. Inclusive la literatura médica, al analizar el uso de armas convencionales en conflictos armados, invierte el índice para reportar heridos sobre muertos, por ser más comunes los primeros que los segundos en contextos de guerra. Así, por ejemplo, de acuerdo con Coupland \& Meddings (1999), la guerra de Vietnam tuvo una relación de cuatro heridos por cada muerto durante los años 19641973 y el conflicto entre Israel y Líbano tuvo un índice de 4.5 heridos por cada muerto en 1982. Pero el índice se invierte cuando se trata de crímenes de guerra o tiroteos contra civiles (shootings). Los autores reportan hechos como la masacre de Wah Mee en Seattle que dejó trece personas muertas y cero heridas, o el tiroteo en un MacDonald's de San Ysidro, California, en 1984, que causó la muerte de 21 personas y once heridos dando un índice de 1.9. Otros datos coinciden en que, en contextos de guerra, el número de muertos no supera al de heridos. De acuerdo con la Agencia de Inteligencia de la Defensa de Estados Unidos (DIA), durante la guerra del Golfo hubo trescientos mil militares iraquís heridos y cien mil muertos. Eso significa un índice de tres heridos por cada muerto (Crawford, 2013).

Los datos de las fuerzas federales mexicanas analizados muestran índices de letalidad sumamente altos. Con los datos oficiales calculamos que para el periodo 2007-2014 la Policía Federal tiene un saldo en enfrentamientos de 4.8 civiles muertos por cada civil herido, mientras que en el Ejército llega a 7.9. Sin embargo, los valores del índice para cada una de las corporaciones tuvieron una importante variación durante el periodo, tal como se observa en el gráfico 2.

En el caso del Ejército, el índice de letalidad creció año con año entre 2007 (1.6) y 2012 (14.7), en lo que parece haber sido un aprendizaje en la impunidad del uso de la fuerza letal durante la administración de Calderón. Luego, en los dos primeros ańos del gobierno de Peña Nieto, el índice de letalidad del Ejército disminuyó a 7.7 en 2013, pero se incrementa en 2014 a 11.6 muertos por cada herido. Es importante anotar que para 2014 se trata solo de información del primer trimestre del año.

Si comparamos los últimos dos años de la administración calderonista (20112012) con los datos disponibles de la peñista (2013-5 de abril de 2014), el índice de letalidad de la Sedena disminuyó de 11.2 a 8.1. No obstante, es un valor todavía muy elevado y similar al recogido para todo el sexenio de Calderón (7.9).

Si consideramos la base de datos de prensa, el índice de letalidad del Ejército crece entre 2008 (3.4) y 2011 (19.5), para después descender, aunque mantenga 
valores elevados: 16.1 en 2012, 11.8 en 2013 y 7.3 en 2014 (tabla 3). Es decir, si bien los cálculos con base en la información de prensa no siguen año por año la tendencia de los datos oficiales, en términos generales se comportan de modo similar.

Gráfico 2. Índice de letalidad de la Policía Federal y la Sedena (2007-2014)

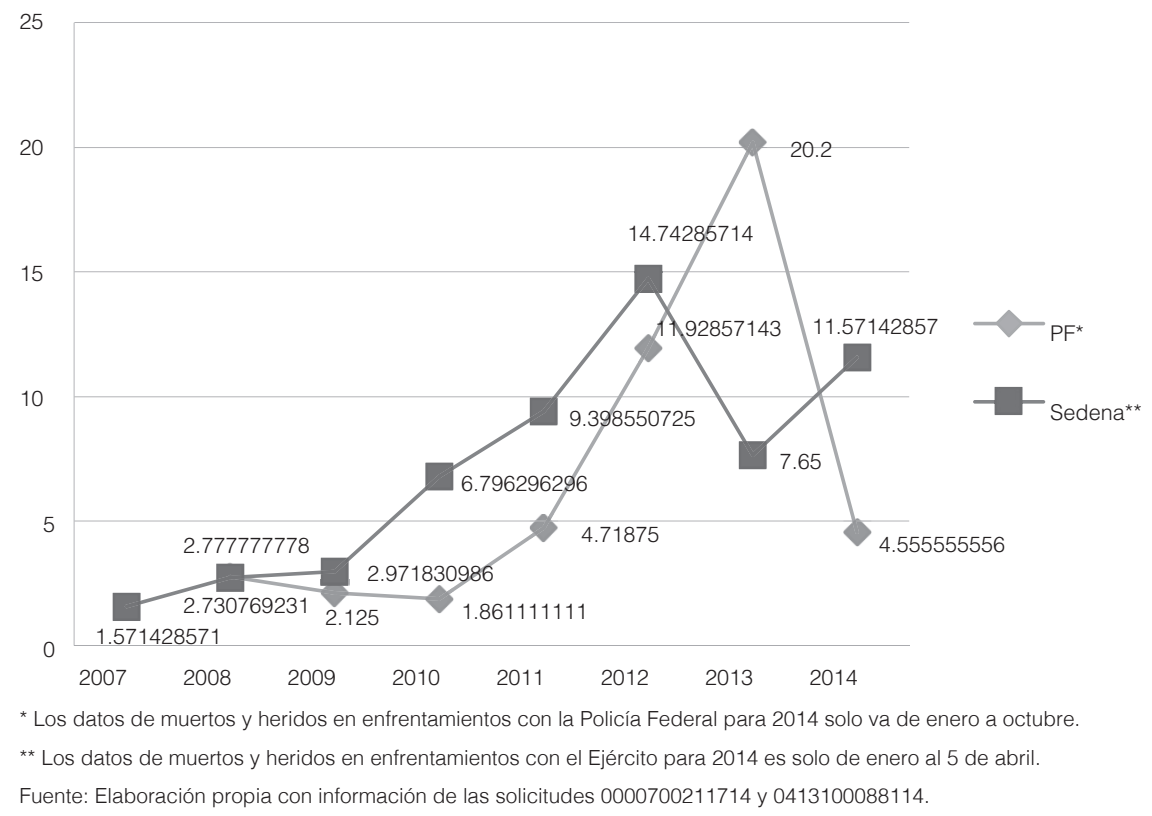

Tabla 3. Civiles muertos y heridos e índice de letalidad en enfrentamientos por fuerza de seguridad federal. Notas de prensa. 2008-2014

\begin{tabular}{|c|c|c|c|c|c|c|c|c|c|}
\hline \multirow[b]{2}{*}{ Año } & \multicolumn{3}{|c|}{ Sedena } & \multicolumn{3}{|c|}{ Policía Federal } & \multicolumn{3}{|c|}{ Marina* $^{*}$} \\
\hline & $\begin{array}{l}\text { Civiles } \\
\text { muertos }\end{array}$ & $\begin{array}{l}\text { Civiles } \\
\text { heridos }\end{array}$ & $\begin{array}{l}\text { Índice de } \\
\text { letalidad }\end{array}$ & $\begin{array}{l}\text { Civiles } \\
\text { muertos }\end{array}$ & $\begin{array}{l}\text { Civiles } \\
\text { heridos }\end{array}$ & $\begin{array}{l}\text { Índice de } \\
\text { letalidad }\end{array}$ & $\begin{array}{l}\text { Civiles } \\
\text { muertos }\end{array}$ & $\begin{array}{l}\text { Civiles } \\
\text { heridos }\end{array}$ & $\begin{array}{l}\text { Índice de } \\
\text { letalidad }\end{array}$ \\
\hline 2008 & 44 & 13 & 3.4 & 44 & 19 & 2.3 & & & \\
\hline 2009 & 95 & 24 & 4 & 74 & 17 & 4.4 & 24 & 6 & 4 \\
\hline 2010 & 327 & 40 & 8.2 & 35 & 9 & 3.9 & 50 & 2 & 25 \\
\hline 2011 & 526 & 27 & 19.5 & 92 & 3 & 30.7 & 103 & 7 & 14.7 \\
\hline 2012 & 370 & 23 & 16.1 & 162 & 13 & 12.5 & 36 & 1 & 36 \\
\hline 2013 & 225 & 19 & 11.8 & 65 & 16 & 4.1 & 33 & 2 & 16.5 \\
\hline 2014 & 168 & 23 & 7.3 & 51 & 2 & 25.5 & 74 & 1 & 74 \\
\hline Total & 1755 & 169 & 10.4 & 523 & 79 & 6.6 & 320 & 19 & 16.8 \\
\hline
\end{tabular}

* En 2008 no se encontraron enfrentamientos con participación de la Semar.

Fuente: Elaboración propia a partir de notas de prensa para el periodo 2008-2014.

344 C. C. Silva Forné, C. Pérez Correa, R. Gutiérrez Rivas | Índice de letalidad 2008-2014: menos enfrentamientos, misma letalidad, más opacidad | Perfiles Latinoamericanos, 25(50) | Flacso México | pp. 331-359 DOI: $10.18504 / \mathrm{pl} 2550-015-2017$ 
El resultado en ambos casos —información oficial y de prensa- es que la letalidad en enfrentamientos de la Sedena tuvo su valor más elevado en 2011 y 2012, pero el descenso posterior aún arroja valores muy altos en un contexto donde la información oficial se cierra al escrutinio público.

En el caso de la Policía Federal, el índice de letalidad en enfrentamientos a partir de datos oficiales conservó valores bajos hasta 2010, pero luego crece vertiginosamente no solo hasta el fin del gobierno de Calderón, sino hasta el primer ańo del actual (2013) llegando a 20.2 civiles muertos por cada herido, número que supera al del Ejército en 2012. Aun así, en 2014 los datos descienden con fuerza: 4.6 civiles muertos por cada herido.

Si comparamos los últimos dos años de la administración calderonista (20112012) con los datos disponibles de los dos primeros años de la actual para la Policía Federal (2013-octubre de 2014), a diferencia de la Sedena, el índice de letalidad aumenta significativamente pues pasa de 6.9 a 10.1 (sin incluir el evento de Tanhuato, Michoacán, donde fallecieron 42 civiles y no hubo heridos). La diferencia es más profunda si se compara el índice de letalidad de la Policía Federal al inicio de la actual administración (10.1) con su valor de todo el sexenio previo (4.2).

El cálculo del índice de letalidad de la Policía Federal con los datos de prensa muestra también valores bajos hasta 2010. En 2011 se dispara a 30.7 y enseguida presenta fuertes bajas y aumentos: 12.5 en 2012, 4.1 en 2013 y 25.5 en 2014. Hay que tomar en cuenta que existen pocos heridos en los enfrentamientos reportados en la prensa, por lo que pequeños cambios en el denominador de un año al siguiente hacen variar significativamente el valor del índice.

Con respecto a la Semar, como ya se refirió, la información oficial no permite calcular el índice de letalidad dado que en la columna de "civiles heridos" señaló "sin datos" en $85 \%$ de los enfrentamientos reportados. Pero si consideramos la información de prensa, el índice de letalidad ha permanecido siempre en valores muy elevados: 25 en 2010, 14.7 en 2011, 36 en 2012, 16.5 en 2103 y 74 en 2014 . Sería necesario contar con los datos oficiales debido a los posibles sesgos de los de la prensa; sin embargo, con base en estos últimos, el índice de letalidad de la Marina alcanza valores que apuntan hacia posibles ejecuciones extrajudiciales.

Como se observa, es claro el aumento del índice de letalidad del Ejército y de la Policía Federal durante el gobierno de Calderón (2007-2012). En los dos primeros años del actual (2013-2014), y en el contexto de un decremento significativo del número de enfrentamientos con presuntos miembros de la delincuencia organizada, la letalidad de las fuerzas de seguridad federales para todo el país muestra: a) una posible tendencia a la baja para la Sedena, pero con valores aún muy elevados en un marco de mayor opacidad que impiden 
evaluar de forma cierta estos valores; $b$ ) una mayor letalidad de la Policía Federal al compararse con los años finales de la anterior administración, y $c$ ) valores siempre preocupantes de la Marina a partir de los datos de prensa y una información oficial que en términos prácticos es inexistente.

4) Índice de letalidad en entidades federativas. Si analizamos la información de algunas entidades federativas donde ha habido mayor presencia de fuerzas federales, los persistentes focos de preocupación en la actual administración se subrayan. Desde enero de 2013 a marzo de 2014 (la Sedena brindó información sobre muertos y heridos hasta el 5 de abril de 2014), el Ejército mató a 540 civiles en enfrentamientos e hirió a 67, un índice de letalidad de 8.1. En la tabla 4 presentamos enfrentamientos, muertos, heridos y el índice de letalidad para algunas entidades federativas seleccionadas donde hubo un número importante de muertos en enfrentamientos durante el mismo periodo.

Tabla 4. Enfrentamientos, civiles muertos y heridos e índice letalidad de la Sedena en entidades federativas seleccionadas. Enero 2013-5 de abril 2014

\begin{tabular}{lcccc}
\hline Entidad federativa & $\begin{array}{c}\text { Número de } \\
\text { enfrentamientos }\end{array}$ & $\begin{array}{c}\text { Civiles muertos en } \\
\text { enfrentamientos }\end{array}$ & $\begin{array}{c}\text { Civiles heridos en } \\
\text { enfrentamientos }\end{array}$ & \begin{tabular}{l} 
Índice de letalidad \\
\hline Tamaulipas
\end{tabular} \\
Guerrero & 309 & 190 & 32 & 5.9 \\
Zacatecas & 67 & 79 & 3 & 26.3 \\
Veracruz & 24 & 58 & 1 & 58 \\
Coahuila & 18 & 49 & 3 & 16.3 \\
Estado de México & 25 & 45 & 2 & 22.5 \\
\hline
\end{tabular}

Fuente: Elaboración propia con información de la solicitud 0000700211714.

Es en Tamaulipas donde se ha dado la mayor cantidad de muertos en enfrentamientos, con un índice de letalidad de 5.9. No se trata de un valor "bajo" para un indicador cuyo estándar señala que debe ser cercano a la unidad, ni significa que en dicho contexto no pudo haber un uso indebido y desproporcionado de la fuerza. Pero el dato parece bajo si se lo compara con otros estados donde casi no hay civiles heridos como saldo de los enfrentamientos.

Destaca el índice de letalidad de Guerrero (26.3) y Zacatecas (58). En el Estado de México, según cifras de la Sedena, durante 2013 y hasta el 5 de abril de 2014, hubo 17 enfrentamientos en los que participó el Ejército donde murieron treinta civiles y hubo un solo herido; tres meses más tarde en Tlatlaya se sumarían 22 muertos más y ningún herido a dichas cifras.

Para la Policía Federal el número de muertos y heridos en enfrentamientos es menor en comparación con el del Ejército, pero para el periodo enero 2013-oc- 
tubre 2014, su índice de letalidad se eleva: 10.1 (141 muertos y 14 heridos), una cifra preocupante para un fuerza policial con un perfil militarizado pero que antes no presentaba un índice de letalidad tan alto. En la tabla 5 se han seleccionado de algunos estados del país los datos para enfrentamientos, civiles muertos, civiles heridos y el índice de letalidad de la Policía Federal.

Tabla 5. Civiles muertos y heridos e índice letalidad de la Policía Federal en entidades federativas seleccionadas. Enero 2013-marzo 2014

\begin{tabular}{lcccc}
\hline Entidad federativa & $\begin{array}{c}\text { Número de } \\
\text { enfrentamientos }\end{array}$ & $\begin{array}{c}\text { Civiles muertos en } \\
\text { enfrentamientos }\end{array}$ & $\begin{array}{c}\text { Civiles heridos en } \\
\text { enfrentamientos }\end{array}$ & Índice de letalidad \\
\hline Tamaulipas & 88 & 55 & 7 & 7.9 \\
Michoacán & 42 & 32 & 4 & 8 \\
Zacatecas & 9 & 14 & 0 & - \\
Guerrero & 17 & 17 & 0 & - \\
\hline
\end{tabular}

Fuente: Elaboración propia con información de la solicitud 0413100088114.

Se observa que en Tamaulipas y Michoacán es donde más civiles han fallecido en enfrentamientos con la Policía Federal a la vez que sus índices de letalidad son elevados (7.9 y 8, respectivamente). En Zacatecas y Guerrero, si bien tienen un menor saldo de civiles muertos, el índice de letalidad no puede calcularse por no existir civiles heridos.

\section{Evaluación de uso de la fuerza y transparencia}

Como ya se mencionó, no existen valores límites únicos que permitan determinar si en una situación específica se usó o no la fuerza letal de forma proporcional y razonable, ni tampoco para evaluar el comportamiento de un cuerpo de seguridad en general. Por ello es fundamental poder contar con toda la información necesaria que conduzca a evaluar el uso de la fuerza con más precisión. En este artículo, utilizamos dos indicadores como herramienta de aproximación al uso de la fuerza letal de los cuerpos federales de seguridad: número de civiles muertos por cada policía o miembro de otra fuerza de seguridad muerto en enfrentamientos, y número de civiles muertos por cada civil herido en enfrentamientos (índice de letalidad). Para construir estas indicadores solicitamos información a las diversas dependencias: Sedena, Semar y Policía Federal.

La primera respuesta que obtuvimos por parte de la Sedena señalaba que no podía dar información sobre civiles muertos y heridos en enfrentamientos debido a que: 
El personal de esta Secretaría después de repeler una agresión, se limita únicamente a preservar el lugar de los hechos, y una vez que hacen presencia las autoridades competentes, se desliga de los procesos e investigación correspondientes. [...] Por lo anterior [...] se le sugiere canalizar su solicitud a la unidad de enlace de la Procuraduría General de la República, a fin de que le proporcione la información que requiere, ya que los datos que solicita, se encuentran dentro de las atribuciones exclusivas de citada Procuraduría.

Con motivo de lo anterior realizamos una solicitud a la PGR (folio 0001700326814) requiriendo la misma información. En esta solicitud se hizo hincapié en lo referido por la respuesta de la Sedena. La PGR contestó que solo contaban con la información que resume la tabla 6 .

Tabla 6. Información sobre civiles muertos, detenidos y heridos en enfrentamientos

\begin{tabular}{|c|c|c|c|c|c|c|c|c|c|}
\hline Periodo & $\begin{array}{l}\text { Dic. } \\
2006\end{array}$ & 2007 & 2008 & 2009 & 2010 & 2011 & 2012 & 2013 & 2014 \\
\hline Enfrentamientos & 0 & 0 & 0 & 0 & 1 & 0 & 1 & 0 & 3 \\
\hline Civiles muertos & 0 & 0 & 0 & 0 & 2 & 0 & 6 & 0 & 34 \\
\hline Detenidos & 0 & 0 & 0 & 0 & 4 & 0 & 2 & 0 & 14 \\
\hline \multirow[t]{3}{*}{$\begin{array}{l}\text { Lugar de } \\
\text { enfrentamiento }\end{array}$} & No & No & No & No & $\begin{array}{l}\text { Nuevo } \\
\text { León }\end{array}$ & No & $\begin{array}{l}\text { Tamau- } \\
\text { lipas }\end{array}$ & No & $\begin{array}{c}\text { Luvianos, } \\
\text { Estado de } \\
\text { México }\end{array}$ \\
\hline & & & & & & & & & $\begin{array}{l}\text { Tihuatlán, } \\
\text { Veracruz }\end{array}$ \\
\hline & & & & & & & & & $\begin{array}{l}\text { Tlatlaya, } \\
\text { Estado de } \\
\text { México }\end{array}$ \\
\hline
\end{tabular}

Fuente: Elaboración propia con datos proporcionados por la PGR a la solicitud folio 0001700326814.

Es decir, que mientras en 2012 la Sedena reportó 814 enfrentamientos y la Policía Federal 142, la PGR reporta tener conocimiento de uno. Para 2013, la Sedena reporta 482 enfrentamientos y la Policía Federal 113, pero la PGR afirma que no registró ninguno. Mientras que en 2014 la PGR reporta tres enfrentamientos que coinciden con los eventos que tuvieron mayor cobertura mediática.

Se interpuso un recurso para impugnar la contestación de la Sedena sobre la inexistencia de información en su haber. En su respuesta, la dependencia proporcionó la información sobre "presuntos agresores muertos y heridos consecuencia de agresiones contra personal militar" del año 2007 al 5 de abril de 2014, señalando que:

[...] a partir del 06 de abril de 2014, ya no se le da continuidad a dicha estadística, en relación de no ser necesaria para esta Dependencia del Ejecutivo Federal, 
debido a que, como ya se le indicó con anterioridad, el personal de esta Secretaría después de repeler una agresión, se limita únicamente a preservar el lugar de los hechos y una vez que hacen presencia las autoridades competentes, se desliga de los procesos e investigación correspondientes. (Las negritas son nuestras.)

Sin duda, una de las principales preocupaciones que surgen de este estudio es la decisión por parte de la Sedena de no continuar recabando la información sobre su actuar durante los enfrentamientos. Esta decisión vulnera el principio de transparencia que exige que los órganos del Estado den a conocer sus actuaciones haciendo posible su evaluación. No se debe pasar por alto que el artículo $7^{\circ}$ de la Ley Federal de Transparencia y Acceso a la Información Pública Gubernamental establece que:

Art. 7-. Con excepción de la información reservada o confidencial prevista en esta Ley, los sujetos obligados deberán poner a disposición del público y actualizar, en los términos del Reglamento y los lineamientos que expida el Instituto o la instancia equivalente a que se refiere el Artículo 61, entre otra, la información siguiente: [...]

XVII. Cualquier otra información que sea de utilidad o se considere relevante, además de la que con base a la información estadística, responda a las preguntas hechas con más frecuencia por el público.

Por otro lado, la determinación de la Sedena de no recabar información también viola las leyes que rigen el uso de la fuerza por parte de las instituciones federales. El Manual del Uso de la Fuerza de Aplicación Común a las Tres Fuerzas Armadas en su artículo 14 señala que después de una agresión y:

1. Cuando en el lugar de los hechos resultaran personas civiles o militares muertos o heridos, y se encuentre presente la autoridad civil, se procederá:

$[\ldots]$

iii. Elaborar un informe detallado del evento donde se efectuó uso de la fuerza de conformidad con las disposiciones que sobre el particular emitan ambas secretarías.

Resulta pues contradictorio que la Sedena afirme que la información sobre civiles muertos y heridos no es necesaria para la dependencia, cuando las leyes que regulan su actuación así lo requieren. La decisión no solo se traduce en una violación del principio de legalidad y transparencia sino también del derecho a la vida. Como ha expresado la Oficina del Alto Comisionado en Derechos Humanos de Naciones Unidas a través del Relator Especial sobre Ejecuciones Extrajudiciales, la falta de información de los países en este tema "refleja una falta 
de rendición de cuentas y, por ende, una violación general del derecho a la vida" (ONU, 2014: punto 136). Esto es así porque dicha información es relevante para mejorar los controles del uso de la fuerza. Y sin dichos controles habrá mayores incentivos para que los miembros de los cuerpos de seguridad utilicen la fuerza pública, incluida la letal, de forma ilegal, desproporcionada e innecesaria. ${ }^{21}$ En este sentido, la Corte Interamericana de Derechos humanos ha destacado que "los Estados deben vigilar que sus cuerpos de seguridad, a quienes les está atribuido el uso legítimo de la fuerza, respeten el derecho a la vida de quienes se encuentren bajo su jurisdicción" (Corte IDH, 2007: punto 81).

Ante idéntica solicitud, la Secretaría de Marina únicamente proporcionó la información de 2012 a 2014, debido a que los datos del periodo 2006-2011 ya no obran en sus archivos por haberse cumplido el tiempo señalado para su conservación. Sorprende en esta respuesta que no exista información sobre la actuación de la dependencia en la administración anterior, como si el cambio de administración implicara el nacimiento de una institución distinta. Por otro lado, como ya se ha señalado, la Semar dijo no tener datos de la gran mayoría de la información solicitada, por lo que su respuesta no permite el análisis de su actuación ni representa un ejercicio de rendición de cuentas.

La Policía Federal entregó información que abarca del 1 de abril de 2007 al 5 de noviembre de 2014. En una solicitud distinta hecha ante la misma dependencia (Policía Federal, con folio 0413100104114), se solicitó que se indicara si en cada enfrentamiento participaron o estuvieron involucradas otra u otras autoridades. La respuesta fue la siguiente:

La información que este Órgano Administrativo Desconcentrado proporcionó [...] únicamente es la relativa a número de enfrentamientos armados en los que ha participado esta Policía Federal con grupos de delincuencia organizada, es decir el registro de las acciones en las que los integrantes de esta Institución Policial fueron agredidos sin que hubiera intervención de otra corporación policial o de las fuerzas armadas. Por lo tanto, en dicha estadística no se encuentran consignados los enfrentamientos en los que ha participado Policía Federal en coordinación con otras instancias.

La generación y disponibilidad de información sobre el uso de la fuerza es indispensable para poder vigilar su uso, sobre todo la letal, por parte de las autoridades. Preocupa así que ni la Fuerzas Armadas ni las autoridades civiles den

21 El prólogo del Manual del Uso de la Fuerza de Aplicación Común a las Tres Fuerzas Armadas establece que el uso de la fuerza debe de regirse "bajo los principios de oportunidad, proporcionalidad, racionalidad y legalidad” (Sedena \& Semar, 2014). 
seguimiento puntal a los resultados de los enfrentamientos y que no generen información para evaluar su propio desempeño y la legalidad de este.

\section{Marco legal en México sobre el uso de la fuerza letal por parte de las fuerzas de seguridad}

El uso de la fuerza letal por parte de los funcionarios encargados de la seguridad, en el marco de un Estado de derecho, debe tener un carácter excepcional y siempre conciliarse con el debido respeto de los derechos humanos. Así se ha establecido en los dos documentos internacionales más relevantes sobre la materia: el Código de Conducta para Funcionarios Encargados de Hacer Cumplir la Ley (Código ${ }^{22}$ y los Principios Básicos Sobre el Empleo de la Fuerza y de Armas de Fuego por Funcionarios Encargados de Hacer Cumplir la Ley (Principios). ${ }^{23}$ Por lo que se refiere al carácter excepcional del uso de la fuerza letal, el artículo 3o. del Código establece que "Los funcionarios encargados de hacer cumplir la ley podrán usar la fuerza sólo cuando sea estrictamente necesario". Por su parte, los Principios también parten del principio de excepcionalidad del uso de la fuerza subrayando en el artículo $4^{\circ}$ que los funcionarios "podrán utilizar la fuerza y armas de fuego solamente cuando otros medios resulten ineficaces". Por lo que toca a la protección de los derechos humanos, el Código señala en su artículo 2o. que "en el desempeño de sus tareas, los funcionarios encargados de hacer cumplir la ley respetarán y protegerán la dignidad humana y mantendrán y defenderán los derechos humanos de todas las personas". Se encuentra una redacción similar en el apartado introductorio de los Principios cuyo séptimo párrafo establece que "el empleo de la fuerza [...] debe conciliarse con el debido respeto de los derechos humanos". En relación con dichos contenidos es importante subrayar que el artículo 8o. de este último documento establece que "No se podrán invocar circunstancias excepcionales tales como la inestabilidad política interna o cualquier otra situación pública de emergencia para justificar el quebrantamiento de estos Principios Básicos".

Más allá de los contenidos del Código y los Principios, en esta sección interesa analizar los esfuerzos que desde el ámbito normativo ha emprendido el gobierno mexicano, a través de la Sedena, para regular el uso de la fuerza letal. Centraremos nuestra atención en dos normas de reciente creación sobre la materia. La primera, expedida por la Sedena, fue denominada Directiva que

22 Resolución 34/169 de la Asamblea General de las Naciones Unidas, aprobada el 17 de diciembre de 1979.

23 Adoptados en el Octavo Congreso de las Naciones Unidas sobre Prevención del Delito y Tratamiento del Delincuente el 7 de septiembre de 1990 en la Habana, Cuba. 
Regula el Uso Legítimo de la Fuerza por parte del Personal del Ejército y Fuerza Aérea Mexicano (Directiva). ${ }^{24}$ La segunda, es el Manual de Uso de la Fuerza de Aplicación Común a las Tres Fuerzas Armadas (Manual). ${ }^{25}$ Conviene analizar algunos de los elementos más destacados de ambos instrumentos para entender el marco legal en el que se está haciendo uso de la fuerza letal en el país y la relación que ello tiene con el derecho a la información y la transparencia que son los principales ejes de este trabajo.

La Directiva fue el primer documento, hoy vigente, elaborado dentro del derecho interno y conviene comenzar destacando - como lo enfatiza su artículo primero- que es de carácter obligatorio y debe ser observado por todo el personal del Ejército y la Fuerza Aérea Mexicana. Siguiendo las normas establecidas en el derecho internacional, este instrumento comienza enfatizando que el personal militar debe respetar y proteger en todo momento los derechos humanos $\left(\right.$ art. $2^{\circ}$ ). Sin embargo, lo que aquí interesa analizar es el contenido del artículo 6o. donde se encuentran establecidos los cuatro principios que deben guiar al personal militar en el uso de la fuerza: oportunidad, proporcionalidad, racionalidad y legalidad. En ese mismo artículo tales principios se definen de forma muy general señalando que el uso de la fuerza es oportuno cuando se utiliza en el momento que se requiere; proporcional cuando se utiliza en la magnitud, intensidad y duración necesarias para lograr el control de la situación, atendiendo al nivel de resistencia que enfrentan las fuerzas de seguridad; racional cuando el uso de la fuerza es producto de una decisión que valora objetivos perseguidos, circunstancias y capacidades tanto del Ejército como de los sujetos a controlar; y legal cuando su uso se desarrolla con apego a la normatividad y respetando los derechos humanos. Si bien se trata de definiciones con las que se busca aterrizar los mandatos establecidas en los Principios y el Código internacionales, a la vez, como puede observarse, se trata de definiciones muy generales, bastante ambiguas que dejan abiertos márgenes de discrecionalidad poco convenientes. Aun así es importante subrayar que la Directiva determina que en el uso de la fuerza se deberán siempre privilegiar las estrategias disuasivas o de persuasión, y solo en el caso de que esté en riesgo la vida o la integridad física del personal militar o de terceros se podrá llegar al último escalón de la fuerza (art. 9, fracción IV). Por lo que se refiere al tema de la información y la transparencia, es importante subrayar, como se hizo arriba, que el artículo 14 determina la obligación del personal militar de elaborar un informe detallado cada vez haga uso de la fuerza. Asimismo, cuando el uso de la misma provoque lesiones o muertes, el personal militar deberá preservar el lugar de los hechos y los indicios

\footnotetext{
24 Publicada el 23 de abril de 2012 en el Diario Oficial de la Federación.

25 Publicado el 30 de mayo de 2014 en el Diario Oficial de la Federación.
} 
(art. 15). Estos elementos responden a las obligaciones fijadas en los Principios creados por Naciones Unidas cuyo artículo $11 \mathrm{f}$ ) exige que se "establezca un sistema de presentación de informes siempre que los funcionarios encargados de hacer cumplir la ley recurran al empleo de armas de fuego en el desempeño de sus funciones". Si dicho uso se considera indebido (lo que de acuerdo con el artículo $6^{\circ}$ supone ser inoportuno, desproporcionado o irracional), la propia autoridad militar deberá denunciarlo ante la autoridad competente (art. 16) para que se puedan deslindar las responsabilidades y aplicar las sanciones que determinen las leyes aplicables (art. 17).

Por su parte, el Manual se elaboró con el objetivo explícito de dar cumplimiento a la Directiva. ${ }^{26}$ En ese sentido, conviene destacar que por tratarse de un Manual cuyo propósito es hacer operativa una Directiva obligatoria, este carácter (obligatorio) también se extiende al Manual, cuyos contenidos son de observancia para todo el personal de las Fuerzas Armadas.

En al capítulo 1, apartado 3, de dicho documento se encuentran desarrollados los principios aplicables al uso de la fuerza. Vuelve a ser importante subrayar que allí se señala que el uso de la fuerza por parte de los integrantes de las Fuerzas Armadas solo es procedente cuando es estrictamente inevitable o indispensable, destacando con ello por cuarta ocasión el carácter excepcional de su uso. Además reitera que tal uso de la fuerza se realizará en estricto apego a los derechos humanos, independientemente del tipo de agresión que las fuerzas enfrenten (3 B). En la definición de los principios, el Manual es un poco más preciso que la Directiva. Por lo que toca a la oportunidad, dicha norma establece que "se debe evitar todo tipo de actuación innecesaria cuando exista evidente peligro o riesgo para la vida de personas ajenas a los hechos". En relación con la noción de proporcionalidad, el Manual también avanza un par de criterios más allá de lo que lo hace la Directiva. Define la proporcionalidad como la relación entre la amenaza al bien jurídico tutelado y el nivel de fuerza utilizado para neutralizarla. En otras palabras, el grado de fuerza utilizado por los agentes del Estado debe ser proporcional a la gravedad de la amenaza en que se encuentre el personal militar o la población civil ajena a los hechos. Por su parte, la gravedad de la amenaza — según el Manual— se determina por la magnitud de la agresión, la peligrosidad del agresor, las características de su comportamiento ya conocido, la posesión o no de armas, y la resistencia u oposición que estos presenten.

26 El artículo 13 de la Directiva establece que los organismos que conforman el Ejército deberán elaborar los manuales y protocolos de actuación específica que prevean las circunstancias en las que es procedente el uso de la fuerza, así como las medidas para evitar daños colaterales (sic) por el uso ilegítimo de la misma. 
La noción de racionalidad queda vinculada en el Manual a una decisión que debe poder primero valorar los objetivos que se persigue con el uso de la fuerza, las circunstancias de la agresión, así como las características personales y capacidades del agresor. Es decir — reitera el Manual—, que frente a una intención hostil, las fuerzas federales solo pueden usar la fuerza cuando no puedan recurrir a otro medio alternativo. Finalmente, por lo que toca a la legalidad, el Manual reitera el criterio de la Directiva sin agregar nuevos elementos; el uso de la fuerza debe apegarse a las normas vigentes y a los derechos humanos.

Por todo ello, se vuelve fundamental contar con la información sobre cada incidente en el que se utiliza la fuerza letal, pues sin esta información es imposible determinar la oportunidad, proporcionalidad y racionalidad de la misma.

Es importante destacar que el Manual también desagrega los niveles de resistencia que se le presenten a las fuerzas de seguridad lo mismo que los niveles de uso de la fuerza dejando, como ya se ha dicho, el uso de la fuerza letal como el último escalón. El artículo $6^{\circ}$ señala que en el uso de la fuerza se privilegiará la disuasión o persuasión. Asimismo, el Manual contiene todo un artículo (el 14) en el que identifica acciones que constituyen un uso indebido de la fuerza, por ejemplo: disparar desde o hacia vehículos en movimiento; disparar a través de puertas, paredes y ventanas hacia objetivos que no están plenamente identificados, o bien disparar contra personas que solo se encuentren causando daños materiales. En el artículo 15 se establece un conjunto de acciones previas que las fuerzas federales siempre deben aplicar cuando se prevea la posibilidad de utilizar la fuerza. Algunas de estas acciones son: contar con cámara de videograbación, fotográfica o instrumentos de grabación de sonido, para estar en condiciones de aportar medios de prueba fehacientes sobre la actuación del personal de las Fuerzas Armadas en operaciones; o bien, concienciar al personal para que evite mostrar actitudes agresivas o provocadoras, tomando en cuenta que, en todo momento, se deberán respetar, proteger y garantizar los derechos humanos. En el mismo artículo 15 se implantan las acciones posteriores a la agresión entre las que destacan: procurar o permitir la atención médica de los heridos y, en su caso, su evacuación a la instalación sanitaria más cercana; coordinación con las autoridades civiles correspondientes para apoyarlos en la preservación del lugar de los hechos, absteniéndose de alterarlo y evitar se tergiverse la verdad histórica y jurídica de los mismos; y elaborar un informe detallado del evento donde se efectuó el uso de la fuerza de conformidad con las disposiciones que sobre el particular emitan ambas secretarías.

Como puede observarse, hay un avance en el esfuerzo de armonización de las normas internas en materia de uso de la fuerza para ajustarse a los contenidos de las directivas internacionales. El gran reto que queda es la implementación de las mismas, comenzando por la rendición de informes y generación de 
información en materia de enfrentamientos para que, a partir de ello, se pueda evaluar el desempeño, legalidad y racionalidad que tienen las fuerzas de seguridad en su relación con el uso de la fuerza letal.

\section{Conclusiones}

Los índices aquí expuestos constituyen una clara señal de alarma acerca de un uso excesivo y desproporcionado de la fuerza letal como posible patrón de comportamiento de las fuerzas federales. Aunque el número total de enfrentamientos y muertos en este tipo de eventos ha disminuido bastante desde 2012, la relación entre civiles muertos y miembros de fuerzas de seguridad muertos en enfrentamientos y el índice de letalidad han permanecido altos (y este último, para la Policía Federal, incluso ha aumentado). Estos resultados podrían ser muestra de la inercia del aprendizaje institucional sobre el uso excesivo y desproporcionado de la fuerza letal desde inicios del sexenio de Calderón.

En el estudio de 2011 concluimos que la inclusión del Ejército en tareas de seguridad pública parecía traer consigo un inevitable uso de la fuerza bajo una lógica de guerra. La conclusión, extendible a otras fuerzas militarizadas, es válida hoy como entonces. Eventos como los de Tlatlaya, Apatzingán y Tanhuato/Ecuandureo han llamado la atención de los medios de comunicación y de la sociedad por sus elevados saldos de muertos y por la confirmación —o las dudas - acerca del uso excesivo e ilegítimo de la fuerza por parte de las fuerzas federales de seguridad. Los autores de este artículo compartimos esta preocupación. Sin embargo, nuestro interés no solo se orienta a dichos acontecimientos sino también a visibilizar cada uno de los enfrentamientos donde se ha usado la fuerza con resultados letales. Estos eventos, al analizarlos de forma agregada, muestran un patrón de comportamiento de las fuerzas federales que se aleja de los estándares nacionales e internacionales que exigen que la fuerza se use respetando los principios de excepcionalidad, necesidad y proporcionalidad. Aunque el índice de letalidad - y otros indicadores que hemos consideradono son pruebas por sí solas de la existencia —o ausencia— de ejecuciones extrajudiciales, cuando se presentan sistemáticamente con valores elevados, son un fuerte indicio de una política deliberada o de una práctica normalizada del uso ilegal de la fuerza letal.

En el contexto descrito, resulta apremiante el diseño y puesta en marcha de mecanismos de control efectivos sobre el uso de la fuerza que permitan evaluar la legalidad de las actuaciones de estas instituciones. Es vital contar con la mejor información posible y que cada caso de uso de la fuerza letal por parte del Estado sea investigado a profundidad y se indaguen las circunstancias y 
características de su ejercicio. Sin embargo, la creciente opacidad, especialmente del Ejército, va en sentido opuesto, y junto con la ausencia de un marco legal que regule debidamente el uso de la fuerza, colocan tanto a los agentes del Estado como a la sociedad en una posición de incertidumbre y riesgo. Los escasos controles que hoy tenemos se traducen en un incentivo para que se haga un uso excesivo de la fuerza. La información, como los mecanismos de control, constituye un elemento clave para la salvaguarda del Estado de derecho empezando por los derechos fundamentales de todas las personas, específicamente del derecho a la vida.

\section{Referencias}

Aimar, V. et al. (2005). Política, policía y violencia en la provincia de Santa Fe. En Sozzo, M. (Ed.). Policía, violencia, democracia. Ensayos sociológicos (pp. 15-52). Argentina: Ediciones UNL.

Alston, P. (2010). Report of the Special Rapporteur on Extrajudicial, Summary or Arbitrary Executions, Philip Alston Addendum Study on Targeted Killings. Recuperado de http://www2 .ohchr.org/english/bodies/hrcouncil/docs/14session/A.HRC.14.24.Add6.pdf

Alston, P. (2006). Informe del Relator Especial, Philip Alston, sobre las ejecuciones extrajudiciales, sumarias o arbitrarias. Adición. Misión a Guatemala. Recuperado de http://www .refworld.org.es/publisher,UNHRC,MISSION,,52b04bcd4,0.html

Astorga, L. (2015). “Qué querian que hiciera?”. Inseguridad y delincuencia organizada en el gobierno de Felipe Calderón. México: Grijalbo.

Belur, J. (2010). Permission to Shoot? Police Use of Deadly Force in Democracies. Nueva York: Springer.

Birkbeck, C. \& Gabaldón, L. (2002). Estableciendo la verdad sobre el uso de la fuerza en la policía venezolana. Nueva Sociedad, (182), 47-58.

Cano, I. (2010). Racial Bias in Police Use of Lethal Force in Brazil. Police and Practice Research, 11(1), 31-43.

Cano, I. (2004). La policía y su evaluación. Propuestas para la construcción de indicadores de evaluación del trabajo policial. En Participación ciudadana y reformas a la policía en América del Sur (pp. 97-118). Santiago de Chile: Centro de Estudios para el Desarrollo.

Cano, I. (1997). Letalidade da Ação Policial no Rio de Janeiro. Río de Janeiro: ISER. 
Centro de Estudios Legales y Sociales (CELS). (2002). Violencia y enfrentamientos policiales. Buenos Aires: Centro de Estudios Legales y Sociales.

Chevigny, P. (1995). Edge of the Knife: Police Violence in Americas. Nueva York: New Press.

Chevigny, P. (1993). Urban Police Violence in Brazil: Torture and Police Killings in São Paulo and Rio de Janeiro after Five Years. News From Americas Watch, 5(5), 1-30. Americas Watch and the Center for the Study of Violence at the University of São Paulo. Recuperado de https://www.hrw.org/sites/default/files/reports/BRAZIL935.PDF

Chevigny, P. (1991). Police Deadly Force as Social Control: Jamaica, Brazil and Argentina. Criminal Law Forum, 1(3), 389-425.

Chevigny, P. (1987). Police Abuse in Brazil: Summary Executions and Torture in Sao Paulo and Rio de Janeiro (An Americas Watch Report). Nueva York: Americas Watch Committee.

Comisión Nacional de Derechos Humanos. Recomendación 51/2014. Sobre los hechos ocurridos el 30 de junio de 2014 en Cuadrilla Nueva, comunidad San Pedro Limón, municipio de Tlatlaya, Estado de México. Recuperado de http://www.cndh.org.mx/sites/all/fuentes/ documentos/Recomendaciones/2014/REC_2014_051.pdf.

Corte Interamericana de Derechos Humanos (2007, 4 de julio). Sentencia del caso Zambrano Vélez y otros vs. Ecuador.

Coupland, R. M. \& Meddings, D. R. (1999). Mortality Associated with Use of Weapons in Armed Conflicts, Wartime Atrocities, and Civilian Mass Shootings: Literature Review. British Medical Journal, (319), 407-410.

Crawford, N. (2013). Civilian Death and Injury in the Iraq War, 2003-2013. Recuperado de http://costsofwar.org/sites/default/files/articles/15/attachments/Iraqciv2013.pdf.

Ferri, P. (2014). Exclusiva: Testigo revela ejecuciones en el Estado de México. Esquire, Recuperado de http://www.esquirelat.com/reportajes/14/09/17/esxclusiva-esquire-Testigo-revela -ejecuciones-ejercito/

Del Olmo, R. (1990). El castigo sin derecho a castigar: la violencia policial y la violencia carcelaria. En Segunda ruptura criminológica (pp. 37-68). Caracas: Universidad Central de Venezuela.

Guerrero, E. (2015). ¿Bajó la violencia? Nexos. Recuperado de http://www.nexos.com $. m x / ? p=24035$. 
Guerrero, E. (2011). La raíz de la violencia. Nexos. Recuperado de http://www.nexos.com $. \mathrm{mx} / \mathrm{p}=14318$

Guerrero, E. (2010). Cómo reducir la violencia en México. Nexos. Recuperado de http://www .nexos.com.mx/?p=13997

Jiménez, R. \& Silva, C. (2015). Percepción y evaluación de las instituciones de seguridad y justicia. México: Universidad Nacional Autónoma de México.

Loche, A. (2010). A letalidade da ação policial: parâmetros para análise. Tomo. Revista do Nucleo de Pós-Graduação e Pesquisa em Ciências Sociais, (17), 39-56.

Mars, J. (2002). Deadly Force, Colonialism, and the Rule of Law: Police Violence in Guyana. Westport, CT: Greenwood.

México Evalúa (2012). Seguridad y justicia penal en los estados: 25 indicadores de nuestra debilidad institucional. Recuperado de http://www.mexicoevalua.org/wp-content/uploads/2013/02/ MEX-EVA_INDX_SJPE-LOW.pdf

Organización de las Naciones Unidas (2014, agosto). Informe del Relator Especial, Sr. Cristof Heyns, sobre las ejecuciones extrajudiciales, sumarias o arbitrarias, A/691/150. Recuperado de http://www.acnur.org/t3/fileadmin/Documentos/BDL/2014/9750.pdf?view=1

Organización de las Naciones Unidas (ONU). (1990). Principios Básicos Sobre el Empleo de la Fuerza y de Armas de Fuego por Funcionarios Encargados de Hacer Cumplir la Ley. Adoptados en el Octavo Congreso de las Naciones Unidas sobre Prevención del Delito y Tratamiento del Delincuente el 7 de septiembre de 1990 en la Habana, Cuba.

Organización de las Naciones Unidas (onu). (1979). Código de Conducta para Funcionarios Encargados de Hacer Cumplir la Ley. Resolución 34/169 de la Asamblea General de las Naciones Unidas, aprobada el 17 de diciembre de 1979.

López, M. \& Salazar, C. (2014, 26 de septiembre). Sería una excepción el caso Tlatlaya: Segob, Reforma. Recuperado de http://www.reforma.com/aplicaciones/articulo/default.aspx?id= 350986\&impresion $=1$

Salazar, P. (2012). Crítica de la mano dura: cómo enfrentar la violencia y preservar nuestras libertades. México: Océano.

Secretaría de la Defensa Nacional (Sedena). (2012, 23 de abril). Directiva que Regula el Uso Legítimo de la Fuerza por Parte del Personal del Ejército y Fuerza Aérea Mexicano. Diario Oficial de la Federación. Recuperado de http://www.dof.gob.mx/nota_detalle.php?codigo= $5244755 \&$ fecha $=23 / 04 / 2012$ 
Secretaría de la Defensa Nacional (Sedena) \& Secretaría de Marina (Semar). (2014, 30 de mayo). Manual del uso de la fuerza, de aplicación común a las tres Fuerzas Armadas. Diario Oficial de la Federación. Recuperado de http://dof.gob.mx/nota_detalle.php?codigo=5346857\&fe cha $=30 / 05 / 2014$

Silva, C., Pérez Correa, C. \& Gutiérrez, R. (2012). Uso de la fuerza letal. Muertos, heridos y detenidos en enfrentamientos de las fuerzas federales con presuntos miembros de la delincuencia organizada. Desacatos. Revista de Antropología Social, (40), 47-64.

Skolnick, J. \& Fyfe, J. (1993). Above the Law: Police and the Excessive Use of Force. Nueva York: Free.

Sozzo, M. (2002). Usos de la violencia y construcción de la actividad policial en la Argentina. En Gayol, S. \& Kessler, G. (Comps.). Violencia, justicia y delito en la Argentina (pp. 223-258). Buenos Aires: Ediciones Manantial.

United States Department of State (2015). Mexico 2014 Human Rights Report. Country Reports on Human Rights Practices for 2014. Bureau of Democracy, Human Rights and Labor. Recuperado de http://www.state.gov/documents/organization/236914.pdf

Recibido el 18 de agosto de 2015. Aceptado el 26 de enero de 2017. 